\title{
О.С. Дьяченко
}

Київський національний університет будівництва і архітектури, Київ, Україна

\section{ТЕОРЕТИЧНІ ДОСЛІДЖЕННЯ ПРОСТОРОВИХ КОЛИВАНЬ ВІБРОУСТАНОВКИ 3 ПНЕВМАТИЧНИМИ ВІБРОЗБУДНИКАМИ КОЛИВАНЬ}

\begin{abstract}
Предметом вивчення в статті $є$ аналіз сучасних чисельних методів побудови математичних моделей вібраційних машин і дослідження їх руху. Метою статті є вибір методу побудови математичної моделі вібраційної установки з просторовими коливаннями для ущільнення бетонних виробів та теоретичне дослідження іiі руху, що забезпечить простоту і адекватність отриманої моделі, а також можливість ії використання при подальших дослідженнях і при розв'язуванні інших типів задач. Завдання: виконати теоретичне дослідження моделювання і розрахунку методом скінченних елементів запропонованої схеми вібраційної установки з просторовими коливаннями для ущільнення бетонних сумішей. Використовуваними методами $\epsilon$ метод скінченних елементів. Отримані такі результати. Для побудови математичної моделі, 3 точки зору сучасного підходу ефективним є застосування розрахункових комплексів загального призначення, в основу яких покладені чисельні розрахунки та основні закони теорії пружності, пластичності тощо. Результатами розрахунку конструкцій чисельними методами (наприклад, методом скінченних елементів) є переміщення (деформації), зусилля (напруження) у вузлах сітки конструктивних елементів конструкції. Наведені рівняння законів руху і залежності енергій математичної моделі розробленої вібраційної установки на основі методу скінченних елементів. Висновки. Розрахунок конструкцій за допомогою чисельного методу дозволяє ще на стадії проектування вібраційної установки отримати переміщення і зусилля в конструкції, амплітуди коливань і загальну картину роботи складових конструктивної схеми машини та провести вдосконалення іiї з точки зору раціонального використання матеріалів і покращення іiі робочих характеристик. Встановлено основні закони руху і залежності енергій математичної моделі вібраційної системи на основі методу скінченних елементів. Розрахунки за приведеними залежностями дозволили отримати загальну картину руху вібраційної машини. Застосування такого підходу до реалізації нових проектів дозволить скоротити час на проведення експериментальних досліджень та знаходжень більш раціональних конструктивних рішень при їх проектуванні.
\end{abstract}

Ключові слова: вібраційна установка, ущільнення, просторові коливання, метод скінченних елементів, ефективність, надійність.

\section{Вступ}

Постановка проблеми. Створення вібраційних установок на етапі проектування, здійснювалось розрахунковими методиками згідно вимогам загально будівельних норм 70 років ХХ-го сторіччя. Ці методики не дають змоги коректно змоделювати динамічну поведінку конструкцій систем і елементів вібраційних установок в складних умовах роботи на високих частотах коливань робочого органу і у відповідь на дію зовнішніх впливів і навантажень.

Така обмеженість відомих методів розрахунку конструкцій вібраційних установок стримує можливості створення інструментів математичного моделювання для здійснення досліджень при попередньому їх проектуванні. Зважаючи на вищевикладене, для розрахунку вібраційних установок для ущільнення бетонних сумішей $є$ актуальним розвиток існуючих $\mathrm{i}$ створення нових ефективних схем обчислювальних методів. До таких методів відноситься зокрема метод скінченних елементів, з подальшою їх реалізацією у вигляді ефективних об'єктно-орієнтованих програмних засобів при розрахунку на комп'ютерних системах. Обчислювальні технології механічно-міцнісного аналізу інженерних конструкцій і систем надають можливість здійснювати розрахунки напруженодеформованого стану і динамічної поведінки технологічного обладнання, що мають складну геометрію, різноманітні граничні умови і навантажені довільною конфігурацією зовнішніх впливів на неї.

Аналіз останніх досліджень і публікацій. Дослідженням динаміки машин для ущільнення бетонних сумішей присвячені ряд робіт [1-3]. В роботі [1] наведені теоретичні та експериментальні дослідження машин блочного типу. Враховано вплив оброблювального середовища на рух машин на основі континуальної моделі. В роботах $[2,3]$ розглянуто теоретичні основи теорії коливань вібраційних систем, наведено фізичну сутність поведінки машин і оброблювальних середовищ при вібраційному русі. Огляд і використання принципів скінченних елементів наведено у праці [4]. За методом скінченних елементів крім статичного навантаження, які зазвичай застосовуються, можливо врахувати і динамічні [5]. Важливим аспектом моделювання, $€$ врахування дисипативних властивостей [6], однак потребує уточнення законів їх зміни.

Формулювання мети статті. Основною метою статті є вибір методу побудови математичної моделі вібраційної установки для ущільнення бетонних виробів та теоретичне дослідження її руху.

\section{Виклад основного матеріалу}

Сучасний розвиток вібраційних машин будується на намаганнях поєднати високу ефективність 3 надійністю системи. Висока ефективність обумовлена значними прискореннями в системі, а надійність потребує створення конструкції з підвищеною жорсткістю елементів. Виходячи 3 цих вимог була запропонована схема вібраційної установки 3 просторовими коливаннями для ущільнення бетонних сумішей [7].

Конструкція досліджуваної вібраційної установки 3 просторовими коливаннями для ущільнення бетонних виробів наведена на рис. 1 в трьох проекціях. Віброустановка складається 3 зварної рами 1 
коробчастого перерізу, яка встановлена на гумових пружних опорах 2 на бетонному фундаменті. На рамі 1 приварено формоутвоюючу пластину 3 . Вібраційна установка обладнана чотирма, асиметрично встановленими вібраційними пневматичними збуджувачами коливань 4, які прикріплені до рами за допомогою приварених кріплень. На установці закріплено два незнімних борти 5 , жорстко приварених по торцях рами 1 , один рухомий борт 6 , який кріпиться до рами на завісах 7 , i фіксується болтами 8 . Також для розділення бетонної суміші 11 між плитами, що формуються, використовується магнітний борт 9, і магнітні перегородки 10.

При створенні математичної моделі досліджуваної системи необхідно користуватись принципами, які забезпечать простоту та адекватність моделі а також можливість використання іiї при подальших дослідженнях - розв'язування інших типів задач, зміну вхідних параметрів, властивостей тощо.

При розгляді динамічного процесу взаємодії системи «машина - оброблюване середовище», застосовують комбінований підхід: конструкцію машини вважають системою 3 дискретними параметрами, а середовище моделюють системою 3 розподіленими параметрами. Такий підхід спрощує загальну математичну модель взаємодії машини та середовища, що підлягає обробці, але в той же час не дозволяють виявити процеси, які протікають в конструкції рами або форми машини, що звужує потенціальні можливості при проектуванні, конструюванні та створенні сучасних машин технологічного призначення.

Опис реальних процесів машин під дією статичних і динамічних навантажень може бути реалізований за допомогою диференціальних рівнянь, в яких стан об'єкту дослідження описаний набором деяких параметрів, а зміна стану - швидкістю зміни цих параметрів. Реальні фізичні процеси, які відбуваються у складних системах адекватно можуть бути описані лише нелінійними диференціальними рівняннями. Для побудови математичної моделі, 3 точки зору сучасного підходу, застосовують розрахункові комплекси загального призначення, в основу яких покладені чисельні розрахунки та основні закони теорії пружності, пластичності тощо. Останнім часом такі розрахункові комплекси знайшли широке застосування в різних галузях, в тому числі і машинобудуванні. Результатами розрахунку конструкцій чисельними методами (наприклад, методом скінченних елементів) є переміщення (деформації), зусилля (напруження) у вузлах сітки конструктивних елементів конструкції. Це дозволяє ще на стадії проектування отримати загальну картину роботи складових конструктивної схеми машини та провести вдосконалення іiї з точки зору раціонального використання матеріалів.

Інтегральну оцінку стану металоконструкцій готового виробу можна виконати на основі проведення динамічних випробувань. Ідея таких випробувань

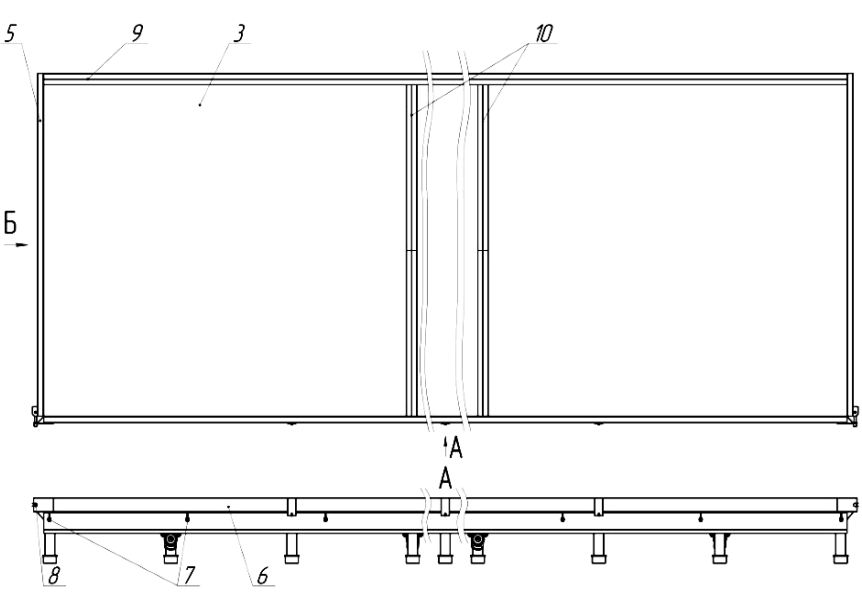

рукція вібраційної установки 3 просторовими коливаннями

полягає у знаходженні дійсних динамічних характеристик конструкції (частоти власних коливань, амплітуди коливань, тощо) 3 подальшим порівнянням цих характеристик з характеристиками, що отримані шляхом математичного моделювання даної системи конструкції. Математична модель має бути створена так, щоб адекватно описувати реальну конструкцію та іiі поведінку при різних навантаженнях, а також здатна відобразити моделювання різного роду недосконалостей пов'язаних 3 виготовленням та безпосередньою експлуатацією за призначенням.

Застосування такого підходу до реалізації нових проектів дозволяє скоротити час на проведення експериментальних досліджень та знаходжень більш раціональних рішень при проектуванні за досить короткий час та 3 мінімальними затратами праці.

Вихідним співвідношенням для отримання основних залежностей, що визначають динамічну поведінку системи, є варіаційні рівняння Гамільтона-Остроградського [4]:

$$
\int_{0}^{t}(\delta U+\delta T+\delta W) d t=\left.\delta q^{T} M \dot{q}\right|_{0} ^{t},
$$

де $\delta U, \delta T, \delta W$ - варіації відповідно потенціальної енергії системи, їі кінетичної енергії та роботи зовнішніх сил; $q, \dot{q}-$ вектор узагальнених переміщень і швидкостей; $\mathrm{t}$ - час. Переміщення точок скінченного елемента стрижня при згині:

$$
w=N q,
$$

де N - матриця інтерполяційних функцій, q - вузлові переміщення в узагальнених координатах.

Матриця інтерполяційних функцій

$$
N=\left[\begin{array}{llll}
N_{1} & N_{2} & N_{3} & N_{4}
\end{array}\right],
$$

$$
\begin{aligned}
& \text { де } \quad N_{1}=1-3 \frac{x^{2}}{a^{2}}+2 \frac{x^{3}}{a^{3}}, \quad N_{2}=x-2 \frac{x^{2}}{a}+2 \frac{x^{3}}{a^{3}} \text {, } \\
& N_{3}=3 \frac{x^{2}}{a^{2}}-2 \frac{x^{3}}{a^{3}}, \quad N_{4}=-\frac{x^{2}}{a}+\frac{x^{3}}{a^{3}} .
\end{aligned}
$$

Вузлові переміщення в цьому випадку будуть прогинами і кутами повороту на кінцях стрижня.

Деформації і напруження у перерізах стрижня закладаються такими рівняннями: 
$\varepsilon=A w=A N q=B q, \sigma=C \varepsilon=C B q$,

де $A=-z \frac{d^{2}}{d x^{2}}, C=E, B=-z \frac{d^{2}}{d x^{2}} N, \mathrm{E}-$ модуль пружності матеріалу.

3 урахуванням (2), (4) варіації потенціальної та кінетичної енергії приймають вигляд:

$$
\begin{aligned}
\delta U & =-\int_{V} \delta \varepsilon^{T} \sigma d V=-\int_{V} \delta(B q)^{T} C B q d V= \\
& =-\delta q^{T}\left(\int_{V} B^{T} C B d V\right) q=-\delta q^{T} K q, \\
\delta T & =\int_{V} \delta \dot{w}^{T} \rho \dot{w} d V=\int_{V}(N \dot{q})^{T} \rho N \dot{q} d V= \\
& =\delta \dot{q}^{T}\left(\int_{V} N^{T} C N d V\right) \dot{q}=\delta \dot{q}^{T} M q,
\end{aligned}
$$

де $\mathrm{K}$ і М матриці жорсткості і мас, $\rho$ - густина матеріалу. Підставляючи (5), (6) в (1) отримаємо:

$$
\int_{0}^{t}\left(-\delta q^{T} K q+\delta \dot{q}^{T} M+\delta W\right) d t=\left.\delta q^{T} M \dot{q}\right|_{0} ^{t},
$$

Після інтегрування маємо рівняння:

$$
\delta q^{T} \int_{0}^{t}\left(M \ddot{q}+K q+\frac{\delta W}{\delta q^{T}}\right) d t=0 .
$$

Враховуючи незалежність варіацій $\delta q^{T}$, рівняння руху елемента:

$$
\begin{gathered}
M \ddot{q}+K q+\frac{\delta W}{\delta q^{T}}=0 . \\
M \ddot{q}+K q=Q(t),
\end{gathered}
$$

де $\mathrm{Q}(\mathrm{t})$ - вектор зовнішніх сил.

Рівняння (10) та вирази для матриць жорсткості (5) і мас (6) прийняті для будь-яких скінченних елементів, тобто $є$ універсальними.

Для системи, яка складається 3 багатьох скінченних елементів будь-яка задача в кінцевому підсумку зводиться до системи рівнянь:

$$
|K|\{q\}=\{R\},
$$

де $\{\mathrm{q}\}$ - вектор переміщень всіх вузлів, $\{\mathrm{R}\}-$ вектор вузлових навантажень.

Рівняння вільних коливань для скінченного елемента одержимо з (10) при умові, що зовнішнє навантаження відсутнє, тобто $\mathrm{Q}(\mathrm{t})=0$ :

$$
M \ddot{w}+K w=0 .
$$

Розв'язок рівняння (12), який відповідає гармонічним коливанням $з$ частотою коливань $\omega$ та фазою $\varphi$.

$$
w=w_{0} \sin (\omega t+\phi),
$$

де $\mathrm{w}_{0}$ - вектор ординат переміщень мас системи відповідно частоті $\omega$. Після підстановки (13) у рівняння (12) одержимо:

$$
\left(K-\omega^{2} M\right) w_{0}=0 .
$$

Рівняння (14) є еквівалентним системі n лінійних алгебраїчних рівнянь щодо компонентів вектора $\mathrm{w}_{0}$ вільних коливань для скінченного елемента оде- ржимо з (10) при умові, що зовнішнє навантаження відсутнє, тобто $\mathrm{Q}(\mathrm{t})=0$. При умові існування ненульових розв'язків, маємо:

$$
\operatorname{det}\left[K-\omega^{2} M\right]=0
$$

Корені рівняння $(15) \omega_{1}, \omega_{2}, \ldots, \omega_{\mathrm{n}} \epsilon$ власні частоти коливань системи. Визначивши корені рівняння (15), знаходимо відповідні вектори w і в остаточному результаті розв'язку маємо $\mathrm{n}$ значень власних частот коливань системи і n відповідних їм векторів.

$$
W=\left[\begin{array}{llll}
w_{11} & w_{12} & \ldots & w_{1 n} \\
w_{21} & w_{21} & \ldots & w_{2 n} \\
\ldots & \ldots & \ldots & \ldots \\
w_{n 1} & w_{n 2} & \ldots & w_{n n}
\end{array}\right] .
$$

Таким чином отримаємо так звану модальну матрицю $\mathrm{W}$, яка фактично і описує форми коливань системи $з$ відповідними значеннями власних частот коливань. Для рішення динамічних задач, рівняння у загальному випадку матиме вигляд [4]:

$$
[M]\{\ddot{q}(t)\}+[C]\{\dot{q}(t)\}+[K]\{q(t)\}=\{0\},
$$

де $[C]=\left[C_{B H}\right]+\left[C_{3 н}\right]-$ матриця коефіцієнтів дисипації, що відповідно враховує внутрішнє розсіювання $[5,6]$, обумовлене властивостями матеріалу скінченного елемента та зовнішнього, яке залежить від загальних характеристик і властивостей системи.

Розв'язок (17):

$$
\{q(t)\}=\{A\} \cdot e^{\lambda t}
$$

де $\{\mathrm{A}\}$ - вектор амплітудних значень вузлових переміщень системи.

Після підстановки (18) у (17) та відповідних спрощень отримаємо систему рівнянь:

$$
\left(\lambda^{2}[M]+\lambda[C]+[K]\right)\{A\}=\{0\},
$$

при умові що

$$
\operatorname{det}\left[\lambda^{2}[M]+\lambda[C]+[K]\right]=0 .
$$

Розв'язок рівняння дає $2 \mathrm{n}$ коренів $\lambda_{\mathrm{n}}$, серед яких є дійні корені $\lambda_{n}=-\alpha_{n} \pm a_{n}$ а також комплексні корені виду $\lambda_{n}=-\alpha_{n} \pm i \bar{\omega}_{n}$. Розрахунки за приведеними залежностями дозволили отримати загальну картину руху вібраційної машини та скоротити час на проведення досліджень.

\section{Висновки}

1.Розрахунок конструкцій чисельним методом дозволив ще на стадії проектування отримати загальну картину роботи складових конструктивної схеми машини та провести вдосконалення її з точки зору раціонального використання матеріалів.

2.Встановлено основні закони руху і залежності енергій вібраційної системи. Застосування такого підходу до реалізації нових проектів дозволить скоротити час на проведення експериментальних досліджень та знаходжень більш раціональних рішень при проектуванні. 


\section{СПИСОК ЛІТЕРАТУРИ}

1. Research and the creation of energy-efficient vibration machines based on the stress-strain state of metal and technological environments. / I. Nazarenko, A. Sviderski, N. Ruchinski, O. Dedov. - The VIII International Conference HEAVY MACHINERY HM 2014, Kraljevo, Serbia, A, 2014. P.85 - 89.

2. Назаренко I.І. Прикладні задачі теорії вібраційних систем. Навч. пос. / I.І.Назаренко. - К.: Слов», 2010. - 440 с.

3. Пановко Я.Г. Основы прикладной теории колебаний и удара. / Я.Г. Пановко. - Л.: Машиностроение, 1976. -320 с.

4. Bathe K. Finite Element Procedures./K. Bathe. - New-York: Prentice Hall, 1996. - 1037 p.

5. Montáns F., Bathe J. Computational issues in large strain elasto-plasticity: an algorithm for mixed hardening and plastic spin. /F. Montáns, J. Bathe// Int. J. Numer. Meth. Enging. - 2005. - № 63. - P. 159-196.

6. Weber G., Anand L. Finite deformation constitutive equations and a time integration procedure for isotropic hyperelasticviscoplastic solids. Computer Methods in Applied Mechanics and Engineering. - 1990. -№ 79. - P. 173-202.

7. Патент України на корисну модель №117955, МПК В28В 1/08(2006.01). Вібраційна установка для формування бетонних і залізобетонних виробів / I.I. Назаренко, П.П. Халімон, О.П. Дедов, О.С. Дьяченко. - № u2017 01755; заявл. 24.02.2017; опубл. 10.07.2017. - Бюл. №13/2017.

Рецензент: д-р техн. наук, проф. К. С. Козелкова, Державний університет телекомунікацій, Київ Received (Надійшла) 27.06.2018 Accepted for publication (Прийнята до друку) 15.08.2018

\section{Теоретические исследования пространственных колебаний виброустановки с пневматическим вибровозбудителем колебаний}

\section{А. С. Дьяченко}

Предметом изучения в статье является анализ современных численных методов построения и исследования математических моделей проектируемых вибрационных машин для определения их движения. Целью статьи является выбор метода построения математической модели вибрационной установки с пространственными колебаниями для уплотнения бетонных изделий и теоретическое исследование её движения, что обеспечит простоту и адекватность полученной модели, и также возможность её использования при дальнейших исследованиях и при решении других типов задач. Задачи: выполнить теоретические исследования моделирования и расчёта методом конечных элементов предложенной схемы вибрационной установки с пространственными колебаниями для уплотнения бетонных смесей. Используемыми методами является метод конечных элементов. Получены следующие результаты. Для построения математической модели, с точки зрения современного подхода эффективным является использование расчётных комплексов общего назначения, в основу каких положены численные расчёты и основные законы теории упругости, пластичности и т.п. Результатами расчёта конструкций численными методами (к примеру, методом конечных элементов) являются перемещения (деформации), усилия (напряжения) в узлах сетки конструктивных элементов конструкции. Приведены уравнения законов движения и зависимости энергий математической модели разработанной вибрационной установки на основе метода конечных элементов. Выводы. Расчёт конструкций при помощи численного метода позволяет ещё на стадии проектирования вибрационной установки получить перемещения и усилия в конструкции, амплитуды колебаний и общую картину работы составляющих конструктивной схемы машины и провести улучшение её с точки зрения рационального использования материалов и улучшения её рабочих характеристик. Установлены основные законы движения и зависимости энергий математической модели вибрационной системы на основе метода конечных элементов. Расчёты по приведённым зависимостям позволили получить общую картину движения вибрационной машины. Использование такого подхода к реализации новых проектов позволить укоротить время на проведения экспериментальных исследований и нахождения более рациональных конструктивных решений при их проектировании.

Ключевые слова: вибрационная установка, уплотнение, пространственные колебания, метод конечных элементов, эффективность, надежность.

\section{Theoretical researches of spatial vibrations of vibration installation with pneumatic vibrator}

\section{O. Diachenko}

The subject matter of the article is the analysis of modern numerical methods for constructing and research of mathematical models of designed vibrating machines, to determine their motion. The goal of the article is to choose a method for constructing a mathematical model of a vibrating installation with spatial vibrations for compacting concrete products and a theoretical study of its movement, which will ensure the simplicity and adequacy of the model obtained, and also the possibility of its use in further research and in solving other types of problems. The tasks to perform theoretical studies of modeling and calculation by the finite elements method of the proposed scheme of a vibration installation with spatial oscillations for compacting concrete mixes. The methods used are: the finite element method. The following results were obtained: for the construction of a mathematical model, from the point of view of the modern approach it is effective to use computation complexes of general purpose, based on numerical calculations and the basic laws of the theory of elasticity, plasticity, and so on. The results of the calculation of structures by numerical methods (for example, by the finite element method) are movements (deformations), forces (stresses) in grid nodes of structural elements of a structure. Presented equations of the laws of motion and the dependence of the energies of the mathematical model of the developed vibration installation on the basis of the finite element method. Conclusions. Calculation of structures with the help of a numerical method allows even at the design stage of a vibration installation to obtain displacements and forces in the structure, the amplitude of the oscillations and the general picture of the operation of the constituents of the structural scheme of the machine and improve it in terms of rational use of materials and improve its performance. The basic laws of motion and energy dependences of the mathematical model of the vibrational system are established on the basis of the finite element method. Calculations by the given dependences made it possible to obtain a general picture of the motion of the vibrating machine. The use of such an approach to the implementation of new projects allows us to shorten the time for conducting experimental studies and finding more rational design solutions when designing them.

Keywords: vibration installation, compaction, spatial oscillations, finite element method, efficiency, reliability. 